\title{
HOMEOPATHY: DO NOT ACCEPT AS MEDICINE WHAT HAS NO EVIDENCE AND CONTRADICTS BASIC SCIENCE
}

Dantas and Fisher state that my review ${ }^{1}$ is "selective" and "biased". It is their comments, though, that I find inaccurate, biased and partial. My review looked at the best possible evidence for homeopathy and made a detailed examination of it, and it would suffice to say that my conclusions are on line with those of many other researchers, e. g $^{2,3,4,5,6,7}$. I will, however, make a detailed analysis of Dantas and Fisher main statements.

1) Dantas and Fisher mention three reviews with positive results for homeopathy. Concerning the first two of them, I am amused by their suggestion that I was "highly selective" and "concealed" their results, since I made clear the reviews did find an effect for homeopathy. However, I went on to analyze their limitations and bias. These limitations have also been discussed by many other authors (e.g. as summarized in ${ }^{5}$ ), and, as I mentioned, were even admitted by the authors of one of that reviews, who substantially reconsidered their conclusions.

Concerning the third review, I reported the results of the best available evidence the review could provide. It surprises me that someone could disagree with this approach.

2) Dantas and Fisher erroneously attributed to me the statement that the bias in the Linde et al review was "difficult to estimate". This statement, inside quotation marks in my paper, actually comes directly from the review $^{8, p 839}$. Also, the sensitivity analysis Dantas and Fisher mention does not consider the composite effect of quality bias, an important point that I dis- cussed at length (in this respect, the reader, as well as Dantas and Fisher, should find interesting the Table 1 in the very didactic Ernst review ${ }^{5}$, or the discussion in ${ }^{9}$ ).

3) My citation of the Linde et al review ("...we found little evidence of effectiveness of any single homeopathic approach on any single clinical condition") is verbatim ${ }^{8, \mathrm{p} 840}$.

4) In my paper, I cited literature reviews and a few studies that I considered illustrative of the negative results of homeopathy. Dantas and Fisher took issue with that, alluding to "systematic reviews and metaanalysis in this area that are positive" (rhinitis, post-operative ileus, arthritis). However, their first reference is a "meta-analysis" with three studies by a same author, which was later contradicted by a study with hundreds of patients (one of the studies I mentioned $\left.{ }^{10}\right)$. The second concerned six studies on post-operative ileus, in which, one more time, a negative result appeared in the largest and best designed study (commissioned by the French government to validate two low-quality studies also included in the review). This review also yielded a negative result for studies above $12 \mathrm{C}$, an information included in my paper, since, as I also discussed, it reveals something about why sometimes a positive result is found for homeopathy. Another reference is a sub-set of six studies from the discussed Linde et al paper, and the other one, with four short-term studies on arthritis, stated that a firm conclusion could not be made, de- spite a positive result. In fact, the authors of this last review thus summarized their conclusions, in a later publication: "no clear trend in favor of homeopathy" 5,p.580.

This adds nothing of substance to my review.

5) Dantas and Fisher allude to "other" inaccuracies that they would not address. This is not a proper way to engage in scientific debate, and all I am left to say is that it sounds like a convenient excuse for avoiding other very damaging points I made, such as the mentioned quality bias in homeopathic studies, contamination problems, the pathetic performance of homeopathy in "provings" and the bizarre physical hypotheses that disguise as "research" among homeopaths.

6) Dantas and Fisher state that I "mock" the possibility of a homeopathic structural effect in water. That they could consider a description of this research "mocking" only comes to show the sad state of affairs in it. As I said, the research history of water physical properties that could be useful for homeopathy is long and unfortunate: water memory, electric ice crystals, water crystals, water clustering, NMR analysis of homeopathic preparations, and the most recent of these, thermoluminescence analysis for homeopathy. Unfortunately, the result of such endeavor has always been the same: studies are later shown to be nonreplicable, the product of contamination, error or simply forthright fraud; and do not add anything to our scientific and medical knowledge. But homeopaths choose to forget past fail- 
ures and cling to another non-blinded, possibly contaminated, still non-replicated study, as if it were solid evidence.

7) Dantas and Fisher say that "homeopathy is remarkably durable". But, of course, they should know that this is not an argument for homeopathy, since many other pseudo-scientific practices also are remarkably durable, such as astrology and iridology. Similarly, the fact that homeopathy sells well, that it is accepted as a medical specialty in a few countries or that the public knows about it is absolutely irrelevant for its validity. Science does not work like that. Thus, the figures they cite only show how strong media misinformation is concerning alternative medical practices; and how desperate homeopaths are to find something that they could bargain as "evidence".

(As for the official recognition of homeopathy by AMB, what the collective wisdom of the literature indicates is that the time has come for AMB to reconsider this tragic mistake.)

8) Dantas and Fisher would like to pretend that they hold some moral high ground on this subject, defending a revolutionary discipline against stubborn skeptics. That is infamous.
But we can remain objective about it. If they suppose that I have been too stern on homeopathy, I make them the same offer I made the president of the AMHB in a $\mathrm{Br}$ Med $J$ debate, and which unfortunately went non-replied $^{11}$ : a chance to really add significant information to our scientific knowledge.

I will select a mother-tincture which they, or whomever they choose, will blindly ingest daily for the time they prefer. After that, according to their symptoms, they will identify which substance was selected.

This simple test is the basis of the "proving" concept in homeopathy, vital for its diagnosing procedures, absolutely feasible and that I would consider convincing proof of the homeopathic effect.

On the other hand, if the information from the provings is unreliable, so is the complex repertorizing-diagnosing-prescribing homeopathic scheme, and the explanation for an occasional positive result in homeopathy should be sought somewhere else.

Alternatively, they could take the US 1000000 prize offered by an American foundation to anyone who could differentiate homeopathy from distilled water using any method (even their favorite one for the moment, thermoluminescence, is acceptable). In case they are not aware of this golden opportunity, I am glad to give them the source: [http://www.randi.org/jr/ 020604monk.html\#8]

However, I have to report that one such attempt has been recently made, to no avail ${ }^{12}$.

Finally, the authors make a travesty of a "scientific call for arms" when they speak of a "collaborative effort" to "understand" homeopathy. Homeopaths are the ones to reject science and deny evidence, holding on to beyond-obsolete notions such as "vital energy", "constitutional types", "miasmas", "aggravations", "provings" and the like. Judging by the current status of homeopathy in Brazil, though, I wouldn't say that this denial has been futile.

Dr. Renan Moritz V. R. Almeida, PhD

Programa de Engenharia Biomédica Caixa Postal 68510

Cidade Universitária

Rio de Janeiro/RJ - Brazil - 21945-970 renan@peb.ufrj.br

\section{REFERENCES}

1. Almeida RMVR. A critical review of the possible benefits associated with homeopathic medicine. Rev Hosp Clin Fac Med S Paulo 2003; 58(6):324-331.

2. Hill C, Dpyon F - Review of randomized trials of homeopathy. Rev Epidemiol Santé Pub 1990; 38:39-47.

3. Kurz R. Clinical medicine versus homeopathy. Paediatric Padology 1992; 27(2):37-41.

4. Aulas J. Homeopathy update. Préscrire Int 1996; 15(155):67484.

5. Ernst E. A systematic review of systematic reviews of homeopathy. Br J Clin Pharmacol 2002; 54(6): 577-582.

6. CRD. Homeopathy. Effective Health Care 2002; 7(3) [Centre for Reviews and Dissemination], University of York, York, UK.

7. Ramey D, Wagner M, Imrie RH et al. Homeopathy and science: a closer look. Available <http://spot.colorado.edu/ vstenger/ Medicine/Homeop.html> - June 2003.
8. Linde K, Clausius N, Ramirez G et al. - Are the clinical effects of homoeopathy placebo effects? A meta-analysis of placebocontrolled trials. Lancet 1997; 350:834-43.

9. Sterne JAC, Egger M, Smith GD. Systematic reviews in health care: investigating and dealing with publication and other biases in meta-analysis. Br Med J 2001; 323:101-105.

10. Lewith GT, Watkins AD, Hyland ME, Shaw S, Broomfield JA, Dolan G, et al. Use of ultramolecular potencies of allergen to treat asthmatic people allergic to house dust mite: double blind randomised controlled clinical trial. $\mathrm{Br}$ Med J 2002; 324(7336):520.

11. Almeida RMVR. Re: Again homeopathy? [British Medical Journal e-letter]. Available <http://bmj.com/cgi/eletters/326/7396/ S151\#3544319>; 20/08/2003.

12. BBC. Homeopathy: The Test - transcript. Available <http:// w w w. b b c.co.uk/science/horizon/2002/ homeopathytrans.shtml>; 28/04/04. 